\title{
CALCIUM ANTAGONISM OF THE BLOCK IN EXCITATION-CONTRACTION COUPLING PRODUCED BY A UREA EXPOSURE- REMOVAL TREATMENT
}

\author{
G. B. Frank and R. C. TrefFers \\ Department of Pharmacology, The University of Alberta, \\ Edmonton, Canada
}

\begin{abstract}
Exposing frog's toe muscles to Ringer's solution made hypertonic with $400 \mathrm{~mm}$ urea for $60 \mathrm{~min}$ followed by placing the muscles back in Ringer's (urea-removal treatment) completely blocks the twitch without disrupting the surface openings of the T-tubules. The urea-removal treatment also increased the triadic junction width. Placing the muscles in Ringer's with an elevated calcium concentration (5 mM) following exposure to the hypertonic solution prevented the block of the twitch response but not the increase in the triadic junction width. Exposing untreated muscles to Ringer's with $5 \mathrm{~mm}$ calcium either had no effect on the twitch or reduced it by $30 \%$ or less. These results suggest the possibility that increasing the width of the triadic junction decreases the amount of calcium ions reaching the terminal cisternae during an action potential thereby blocking the twitch. Elevating the calcium concentration in the T-tubules would increase the amount of calcium which enters the triadic junction during an action potential and thus antagonize the above effects.
\end{abstract}

Several years ago it was demonstrated that the T-tubular system plays an important role in conducting the electrical activity from the surface membrane of frog's twitch skeletal muscle fibres into the interior of the fibres (HuXLEY and TAYLOR, 1958). Later it was found that reexposing skeletal muscle fibres to Ringer's solution following a $1 \mathrm{hr}$ exposure to Ringer's solution made hypertonic by the addition of $400 \mathrm{~mm}$ glycerol disrupted the openings of the T-tubules to the extracellular space of the muscle and simultaneously blocked excitation-contraction (E-C) coupling (GAge and Eisenberg, 1967; Howell and Jenden, 1967; EISENBERG and EISENBERG, 1968).

More recently, Fujino et al. (1972) and Oota and NAGAI (1973) have demonstrated that a similar treatment of skeletal muscle using solutions made

Received for publication January 24, 1977 
hypertonic with urea instead of glycerol also resulted in a block of E-C coupling. However OоTA and NAGAI (1973) observed that this urea-removal treatment did not disrupt or otherwise block the openings of the T-tubules at the surface of the muscle fibres. They attributed the block in E-C coupling to an increased width of the triadic junction produced by the urea-removal treatment.

In the present study it was found that placing a skeletal muscle in Ringer's solution with an elevated calcium concentration (i.e., $5 \mathrm{~mm}$ ) immediately following the period in the hypertonic urea solution antagonized the block in E-C coupling ordinarily produced by the urea-removal treatment. The urea-removal treatment did increase the width of the triadic junction but the increase was not modified by placing the muscle in a solution with an elevated calcium concentration following the urea treatment.

\section{METHODS}

Extensor longus digiti IV (toe) muscles from the frog, Rana pipiens, were used in all experiments.

Mechanical recordings. The muscles were dissected from the frog in a way similar to that described by FRANK (1960) and mounted vertically in a $8 \mathrm{ml}$ bath containing Ringer's solution. The lower end of the muscle was fixed near the bottom of the bath and the upper end was attached to the arm of a strain gauge by means of a silk thread.

Supramaximal, rectangular pulses, $2-5 \mathrm{msec}$ in duration were applied to the muscles by means of two platinum electrodes, one situated at the bottom of the bath and the other at the top part of the bath. The stimulii were applied once every $150 \mathrm{sec}$ prior to and once every $30 \mathrm{sec}$ following urea removal (Figs. 2 and 3). The tension produced was recorded with a strain gauge whose active elements consisted of two pixie transducers in a wheatstone bridge configuration. The output was recorded with a Speed-Servo recorder (Esterline Angus). The resting tension on the muscle was adjusted so that the muscle remained in a vertical position when the bath solution was drained (resting tension $=150-200 \mathrm{mg}$ ). All experiments were carried out at room temperature $\left(20^{\circ} \mathrm{C}\right)$. Muscles were allowed to equilibrate for a period of 40-60 min before an experiment was started.

Electrical recordings. For these experiments the muscles were mounted horizontally in a bath open at the top and viewed from above with a dissecting microscope. Two glass capillary micro-electrodes filled with $3 \mathrm{M} \mathrm{KCl}$ were inserted into the same fibre $<50 \mu \mathrm{m}$ apart in surface fibres. A depolarizing, rectangular current pulse, $1 \mathrm{msec}$ duration was passed through one micro-electrode (resistance, approx. $10 \mathrm{M} \Omega$ ) and the resultant displacement of the membrane and the action potentials were recorded with the other (resistance, 10-40 M $\Omega$ ). In order to produce a 'late negative' after potential 10 stimuli, $10 \mathrm{msec}$ apart were used. 
Solutions. Ringer's solution with the following composition was used (in $\mathrm{mM}): \mathrm{NaCl}, 11.8 ; \mathrm{CaCl}_{2}, 1.08 ; \mathrm{KCl}, 2.47 ; \mathrm{NaHCO}_{3}, 2.38 ; \mathrm{NaH}_{2} \mathrm{PO}_{4} \cdot 2 \mathrm{H}_{2} \mathrm{O}, 0.087$; glucose, 11.1 ; and $d$-tubocurarine, $0.1 \mathrm{mg} / \mathrm{ml}(\mathrm{pH}=7.4)$. The osmolarity of this solution was $235 \mathrm{mosm} / \mathrm{kg}$. High calcium (5 mM) Ringer's solutions were prepared by adding the appropriate amount of calcium chloride to the Ringer's solution. Hypertonic urea solutions consisted of Ringer's solution in which 400 mM urea was added to produce a total osmolarity of $635 \mathrm{mosm} / \mathrm{kg}$.

Electron microscope preparation. For electron microscopy toe muscles were fixed in $5 \%$ gluteraldehyde buffered at $\mathrm{pH} 7.4$ with Millonig's phosphate buffer. Thereafter, the muscles were removed from the bath and stored at $4{ }^{\circ} \mathrm{C}$ in a buffered gluteraldehyde solution until muscles from several experiments had accumulated. Prior to postfixation the muscles were thoroughly washed in phosphate buffer and cut across into strips of tissue 3-4 mm in length. Tissues were postfixed for $40 \mathrm{~min}$ at $4^{\circ} \mathrm{C}$ in $1 \%$ osmium tetroxide buffered with Millonig's buffer solution. The tissue strips were dehydrated in graded concentrations of ethanol followed by propylene oxide and were embedded in Epon 812. Longitudinal sections of the deeper fibres were cut on a Porter-Blum MT-2 ultramicrotome using glass knives. They were mounted on copper grids of 300-mesh, and stained with uranyl acetate $(15 \mathrm{~min})$ followed by lead citrate $(5 \mathrm{~min})$. The sections were examined with an AEI Corinth 275 electron microscope and photographs were taken of intact triad structures ( $\times 60,000$ magnification).

Measurements. The triad apparatus is oriented radially around the individual myofibrils and hence longitudinal sections of the muscle will yield one of the following views of the triad:

a. When the triad is cut in cross section. The plane of section will be perpendicular to the long axis of the transverse tubule (Fig. 1a).

b. When the triad is cut tangentially. The plane of section runs parallel to the long axis of the transverse tubule (Fig. 1c).

c. Anywhere in between these two extremes (Fig. 1b).

For measurements of triadic width micrographs were collected at random with any of the above views. Negatives were enlarged three times $(\times 180,000$ magnification) and printed on photographic paper. Measurements were made of the distance between the outer surface of the T-tubule and the inner aspect of the membrane of the terminal cisternae (i.e. width of triadic junction + two times the width of the unit membrane) by means of vernier calipers. An estimate of the width of the triad junction was obtained by subtraction of 140 Angstrom (two times the width of the unit membrane) from the above measurements. From each photograph of a triad junction four measurements were made (two from each junctional face of the triad) and the mean of these four measurements was recorded. Measurements were made only at positions where the opposing membranes were running parallel and a satisfactory resolution of the membranes was obtained. A total of ten micrographs of different triad structures was selected at random 
from each muscle and measured. The ten means were pooled to produce a mean which was considered to be representative of the population mean of the muscle in question.

a)

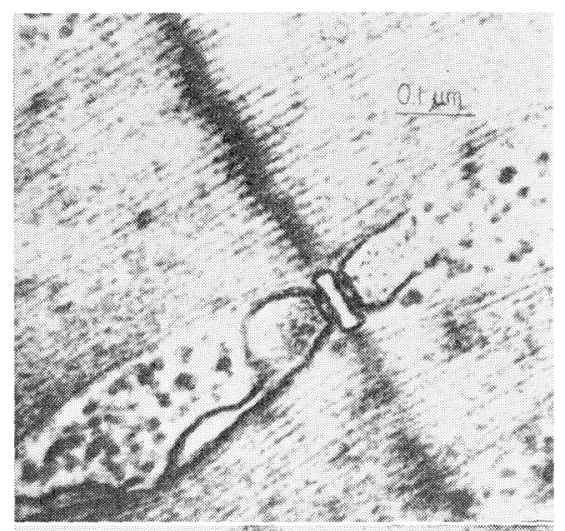

b)
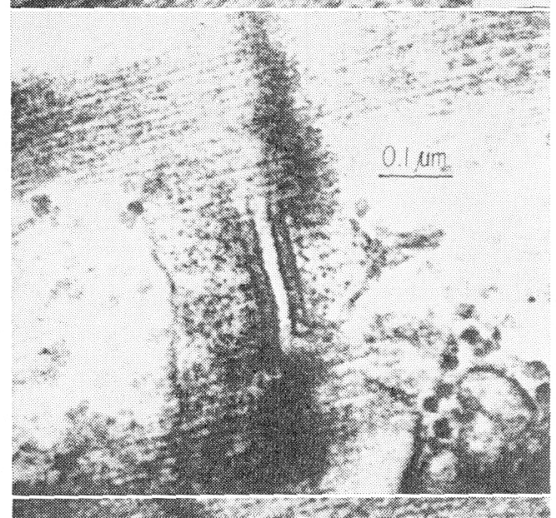

c)

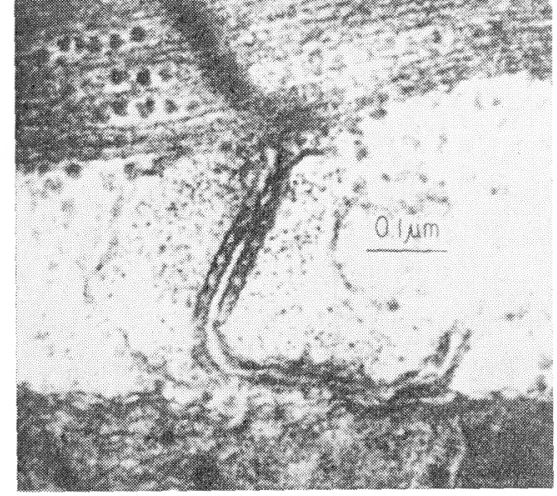

Fig. 1. Variations in the appearance of the triad apparatus seen in longitudinal section micrographs from untreated toe muscles. See text for further details. 


\section{RESULTS}

\section{Effects of urea-removal on the twitch response}

The effect of a hypertonic urea solution and its subsequent replacement with isotonic Ringer's solution (urea-removal) on the twitch tension of a toe muscle is shown in Fig. 2. The muscle was stimulated at constant intervals during the course of the experiment. Immediately upon immersion in the hypertonic urea solution there was a contracture response following which, after about $15 \mathrm{~min}$, a

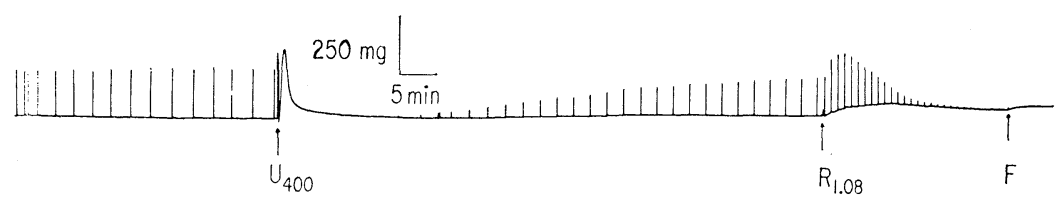

Fig. 2. Effects of the urea-removal treatment on the tension produced by a toe muscle. At $U_{400}$, the muscle was placed in Ringer's with $400 \mathrm{~mm}$ urea; at $R_{1.08}$, the muscle was placed in Ringer's without urea; and at F, the muscle was placed in the fixative solution.

small twitch reappeared and gradually increased reaching maximum tension approximately $60-70 \mathrm{~min}$ following immersion in the urea containing solution. When the muscle was returned to isotonic Ringer's solution the twitch response was initially potentiated but then decreased in size and disappeared within 10 to $25 \mathrm{~min}$ of urea-removal. Despite the loss of the twitch, urea-removed muscles were still able to respond mechanically to caffeine (FuנINo et al., 1972; ОотA and NAGAI, 1973).

The loss of the twitch was prevented when muscles, immersed in hypertonic urea for $60 \mathrm{~min}$, were placed in a $5 \mathrm{~mm}$ calcium-Ringer solution. This is illustrated in Fig. 3 for a single experiment conducted on the two toe muscles from a single frog. A graphical representation of the average time course of decline of twitch tension under conditions of high and normal calcium concentrations is shown in Fig. 4.

In contrast to its effect on urea-removal treated muscles, increasing the calcium concentration to $5 \mathrm{~mm}$ in the solution bathing untreated muscles either had no effect on the twitch or reduced it by $30 \%$ at most.

\section{Measurements of the triadic junction width}

The toe muscles from the right and left foot of each frog were unsystematically assigned as muscle 1 or muscle 2 of each pair. There was no significant difference between the triadic width measurements for the two muscles under the untreated condition (Table 1A).

In the urea-removal experiments, both of the muscles in each pair were fixed simultaneously with gluteraldehyde buffer within a few seconds after the twitch response in muscle $1\left(1.08 \mathrm{mM} \mathrm{Ca}^{++}\right)$had disappeared. The twitch tensions record- 


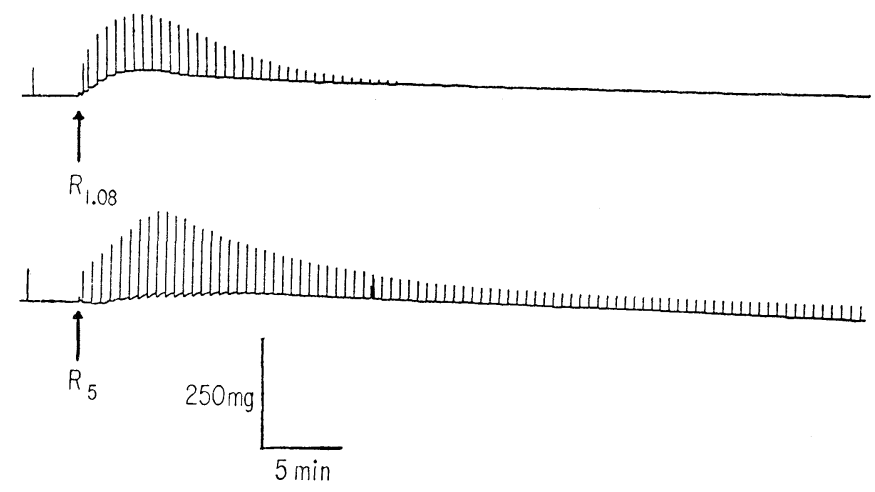

Fig. 3. Prevention of the urea-removal treatment block in excitation-contraction by elevation of the $\mathrm{Ca}^{++}$concentration. Two toe muscles from the same frog mounted in separate baths and tested simultaneously. At $\mathbf{R}_{1.08}$ (upper record), the muscle was

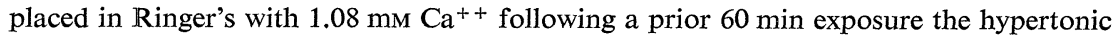
urea containing solution; at $\mathbf{R}_{5}$ (lower record), the muscle was placed in Ringer's with $5 \mathrm{mM} \mathrm{Ca}^{++}$following urea treatment. In most other paired experiments, the muscles were fixed within one min after the twitch had disappeared in the muscle placed in Ringer's with $1.08 \mathrm{~mm} \mathrm{Ca}^{++}$.

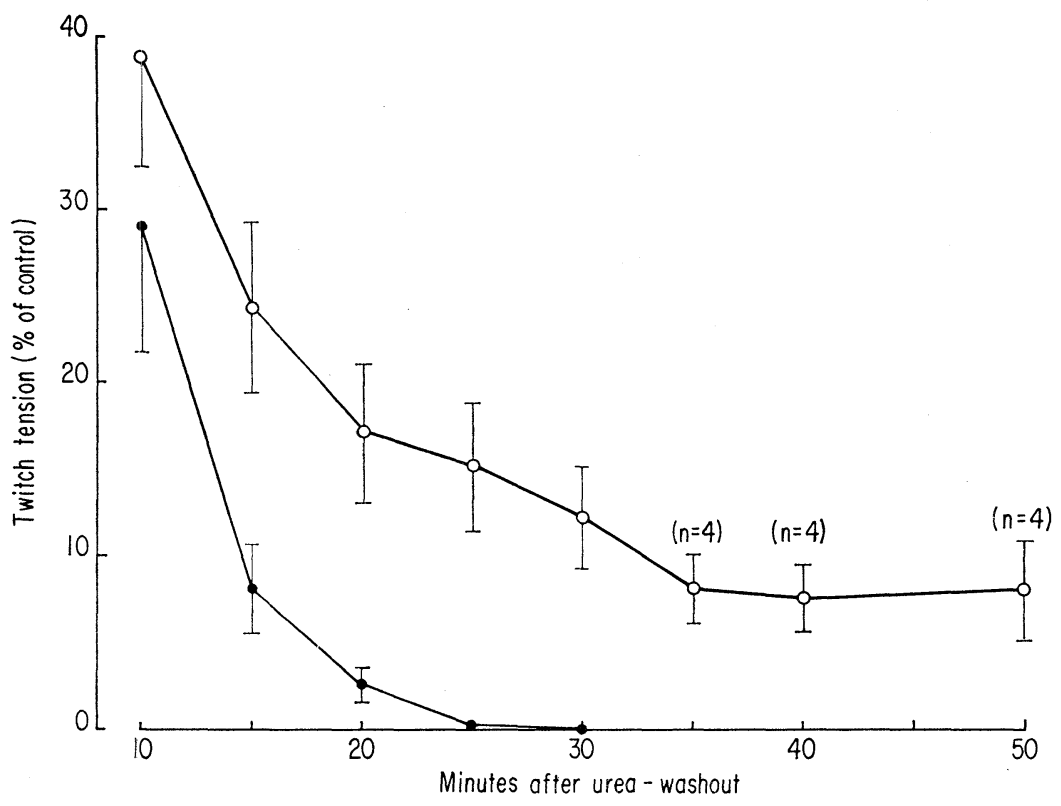

Fig. 4. Time course of the decline in the twitch tension following urea-removal. Except as noted, 10 muscles $(n=10)$ were used to calculate the mean $\pm S E$ for each point. muscles placed in $1.08 \mathrm{mM} \mathrm{Ca}^{++}$Ringer's; $O$, muscles placed in $5 \mathrm{~mm} \mathrm{Ca} \mathrm{Ca}^{++}$Ringer's. Control, maximum twitch tension recorded for each muscle before exposure to the hypertonic urea solution. 
ed at this time for each muscle $2\left(5 \mathrm{mM} \mathrm{Ca}^{++}\right)$are listed in Table 1B. Despite the difference on the twitch response produced by altering the $\mathrm{Ca}^{++}$concentration, there was no significant difference between the triadic widths in muscles 1 and 2 . However, in conformation of the findings of OOTA and NAGAI (1973), a significant increase in the width of the triadic junction was produced by the urea-removal treatment.

Table 1. Measurements of the width of the triadic junction in untreated toe muscles and in muscles subjected to the urea-removal procedure. Triadic junction width listed for each muscle is the mean \pm standard error of the mean (SE) of 10 measurements (see METHODS). Twitch tensions for urea treated muscle 2 recorded just prior to fixation when twitch tension in muscle 1 was zero.

\begin{tabular}{|c|c|c|c|c|c|c|}
\hline \multicolumn{3}{|c|}{ A. Untreated toe muscles } & \multicolumn{4}{|c|}{ B. Urea-removal treated toe muscles } \\
\hline \multirow{2}{*}{ Expt. No. } & \multicolumn{2}{|c|}{ Triadic width $(\AA)$} & \multirow{2}{*}{ Expt. No. } & \multicolumn{2}{|c|}{ Triadic width $(\AA)$} & \multirow{2}{*}{ 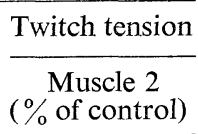 } \\
\hline & Muscle 1 & Muscle 2 & & $\begin{array}{c}\text { Muscle } 1 \\
(1.08 \mathrm{~mm} \mathrm{Ca})\end{array}$ & $\begin{array}{c}\text { Muscle } 2 \\
(5 \mathrm{~mm} \mathrm{Ca})\end{array}$ & \\
\hline $4 / 12$ & $91 \pm 5$ & $84 \pm 4$ & $17 / 9$ & $119 \pm 4$ & $122 \pm 3$ & 16 \\
\hline $5 / 12 \mathrm{a}$ & $92 \pm 5$ & $93 \pm 5$ & $18 / 9$ & $104 \pm 5$ & $107 \pm 5$ & 9 \\
\hline $5 / 12 b$ & $91 \pm 3$ & $93 \pm 5$ & $22 / 9$ & $116 \pm 5$ & $102 \pm 4$ & 2 \\
\hline \multirow[t]{5}{*}{$6 / 12$} & $80 \pm 4$ & $89 \pm 5$ & $23 / 9$ & $121 \pm 5$ & $98 \pm 3$ & 7 \\
\hline & & & $11 / 12$ & $101 \pm 6$ & $110 \pm 3$ & 33 \\
\hline & & & $23 / 12$ & $114 \pm 3$ & $102 \pm 3$ & 18 \\
\hline & & & $15 / 1$ & $107 \pm 3$ & $128 \pm 6$ & 13 \\
\hline & & & $16 / 1$ & $114 \pm 3$ & $109 \pm 3$ & 23 \\
\hline \multicolumn{7}{|l|}{ Muscle means } \\
\hline$\pm \mathrm{SE}^{*}$ & $88.5 \pm 2.8$ & $89.8 \pm 2.1$ & & $112.0 \pm 2.5$ & $109.8 \pm 3.7$ & $15.1 \pm 3.5$ \\
\hline \multicolumn{7}{|l|}{ Treatment } \\
\hline means $\pm \mathrm{SE}^{* *}$ & \multicolumn{2}{|c|}{$89.1 \pm 1.7$} & \multicolumn{4}{|c|}{$110.9 \pm 2.2$} \\
\hline
\end{tabular}

* Triadic width means for muscles 1 and 2 did not differ significantly in A or B: $P>0.5$.

** Triadic width means for urea-removal treated muscles was significantly greater than for untreated muscles: $P<0.001$.

\section{Intracellular microelectrode recordings}

Two types of electrophysiological measurements are often used to determine if the openings of the T-tubules at the surface of the muscle fibres remain intact: 1) the 'Creep' in potential produced by large, prolonged hyperpolarizations, and 2) the 'late negative after potential' which can be recorded following a high frequency burst of action potentials. The presence of either phenomenon is considered to indicate that the surface openings have not been sealed off. In the present study the late negative after potential was produced when using urearemoval treated muscles (Fig. 5).

When the T-tubular openings are sealed off by glycerol treatment the normal negative after potential which follows a single impulse also disappears (GAGE and EISENBERG, 1967). The negative after potential did not disappear in urea-removal 


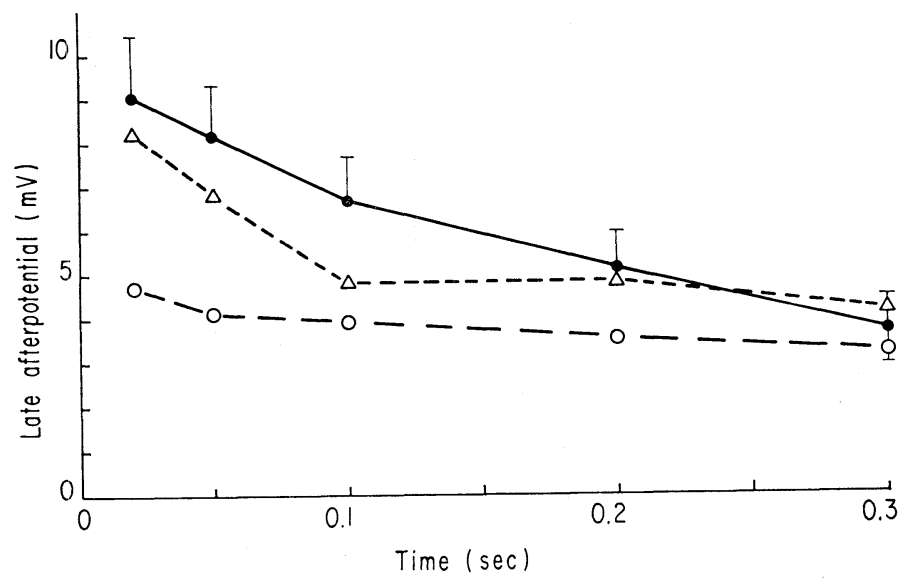

Fig. 5. Late negative after potentials recorded intracellularly in control toe muscle fibres

- in urea-removal treated muscle fibres placed in $1.08 \mathrm{~mm} \mathrm{Ca}^{++}$Ringer's $\bigcirc$ and from fibres placed in $5.0 \mathrm{~mm} \mathrm{Ca}^{++}$Ringer's $\triangle$. 0 , means $\mathrm{SE}$ for 6 muscles $(10$ fibres); $O$, means from 3 fibres in 1 muscle; and $\triangle$ means from 2 fibres in 1 muscle.

treated muscles. These results confirm the histological findings of ОотA and NAGAI (1973) showing the penetration of ferritin particles into the T-tubules of urea-removal treated muscles.

\section{DISCUSSION}

Our present view of the events occurring during E-C coupling in vertebrate skeletal muscles may be summarized briefly as follows: Activation of the intracellular contractile proteins is produced by a sudden increase in the sarcoplasmic $\mathrm{Ca}^{++}$ion concentration. Most or all of this calcium comes from the sarcoplasmic reticulum (SR) where it is stored in the resting fibre (SANDOW, 1965). Depolarization of the 'T-tubular' membrane is required to cause the release of calcium from the SR (GAGE and EISENBERG, 1967). The mechanism by which 'T-tubular' depolarization produces the release of calcium from the SR remains in doubt. Two alternative hypotheses have received the greatest experimental interest: 1) that current flows from the T-tubules through the SR membranes causing calcium release and 2 ) that 'trigger $\mathrm{Ca}^{++}$ions' are released into the triadic junction, diffuse to the SR membrane and act on the SR membrane to stimulate $\mathrm{Ca}^{++}$release (PoDOLSKY, 1975).

The findings of EisENBerg and EISENBERg (1968), GAGE and EISENBERG (1967) and Howell and JENDEN (1967) that glycerol-removed treatment sealed off the surface openings of the T-tubules and thereby blocked E-C coupling in frog's skeletal muscle, demonstrated that activity in the T-tubules is required for E-C coupling but does not help to determine the nature of that activity. The demonstration by OOTA and NAGAI (1973) that a urea-removal treatment blocked 
E-C coupling without sealing off the surface openings of the T-tubules provides a preparation for investigating the nature of the tubular activity required for E-C coupling.

In addition to confirming the findings of OoTA and NAGAI (1973), it was observed in the present study that placing a toe muscle in Ringer's solution with an elevated calcium concentration $(5 \mathrm{~mm})$ following urea-removal treatment prevented the block of E-C coupling produced when using Ringer's with $1.08 \mathrm{~mm}$ calcium. However even with using the elevated calcium Ringer's the twitch amplitude was much smaller than in the control response obtained before exposure to urea (Fig. 4 and Table 1B).

The only structural change produced by the urea-removal treatment noted by OоTA and NAGAI (1973) was an increase in the width of the triadic junction region between the membrane of the T-tubule and the membrane of the terminal cisternae. Although they could not explain the mechanism for the E-C coupling block produced by urea-removal treatment, they did suggest that the increase in triadic junction width was somehow involved. The use of the $5 \mathrm{~mm}$ calcium Ringer's did not prevent nor reduce the increase in triadic junction width (Table 1B). Thus the antagonism of the E-C coupling block by the use of a $5 \mathrm{~mm}$ calcium Ringer's was not due to an effect on the triadic junction width.

There is a measurable influx of $\mathrm{Ca}^{++}$ions with each action potential in frog twitch muscle fibres (BIANCHI and SHANES, 1959). Since the surface area of the T-tubules is several times greater than the outer cylindrical surface of the fibre (e.g. $7 \times$ for a $100 \mu \mathrm{m}$ fibre, PEACHEY, 1965), it would seem reasonable to assume, barring evidence to the contrary, that most of the calcium enters the fibre through the walls of the T-tubules during an action potential. Ionic currents during an action potential are produced by an increase in the membrane permeability to specific ions resulting in an increased movement of the ions down their concentration gradient across the membrane (HoDGKIN and HuXLEY, 1952). Thus in this way, increasing the extracellular $\mathrm{Ca}^{++}$concentration should increase the amount of calcium that enters the triadic junctional space with each action potential. Therefore one possible explanation of the results obtained in these experiments is as follows: The $\mathrm{Ca}^{++}$ions entering the triadic junction diffuse to and interact with the membrane of the terminal cisternae to cause the release of $\mathrm{Ca}^{++}$ions into the sarcoplasm. Increasing the width of the triadic junction would decrease the amount of calcium ions reaching the wall of the terminal cisternae due to the following factors: 1) a decrease in the calcium concentration due to an increase in triadic junction volume; and 2) an increased diffusion of calcium out of the triadic junction due to an increase in the area of direct contact between triadic junction and the sarcoplasm. Increasing the amount of calcium entering with each action potential by increasing the calcium concentration in the T-tubules would compensate, at least in part, for the 2 factors causing a decrease in the amount of calcium ions reaching the walls of the terminal cisternae. Thus pro- 
vided that the increased width of the triadic junction is the cause of the block of E-C coupling in urea-removal treated fibres, the above mechanism would explain the antagonism of the block produced by raising the extracellular calcium concentration.

It would be more difficult to explain the present results on the basis of a current-coupling model for E-C coupling. According to this type of model the block in E-C coupling caused by urea-removal treatment might be due to a decrease in the current crossing the T-tubular walls, a decrease in the current reaching the terminal cisternae, a decrease in the sensitivity of the terminal cisternae to current flow, or some combination of these effects. However, in view of the well known membrane stabilization properties of elevated calcium concentrations (Shanes, 1958; Frankenhauser and Hodgkin, 1957), one would expect that increasing the extracellular calcium concentration 5 fold should reduce the current flow through the T-tubular membrane and thus cooperate with the above effects to intensify the block rather than to antagonize the E-C coupling block as found in the present study.

This work was supported by a grant from the Medical Research Council of Canada.

\section{REFERENCES}

Bianchi, C. P. and Shanes, A. M. (1959) Calcium influx in skeletal muscle at rest, during activity, and during potassium contracture. J. Gen. Physiol., 42: 803-815.

EISENBERG, B. and EisenberG, R. (1968) Selective disruption of the sarcotubular system in frog sartorius muscle. J. Cell Biol., 39: 451-467.

FrANK, G. B. (1960) Effects of changes in extracellular calcium concentration of the potassiuminduced contracture of frog's skeletal muscle. J. Physiol., 151: 518-538.

Frankenhauser, B. and Hodgkin, A. L. (1957) The action of calcium on the electrical properties of squid axons. J. Physiol., 137: 218-244.

Fujino, M., Fujino, S., and Yamaguchi, T. (1972) Significance of transverse tubular system in determining the contractility of frog skeletal muscle. Proc. Jap. Acad., 48: 539-543.

GAGE, P. W. and EISENBERG, R. S. (1967) Action potentials without contraction in frog skeletal muscle fibres with disrupted transverse tubules. Science, 158: 1702-1703.

Hodgkin, A. L. and Huxley, A. F. (1952) Quantitative description of membrane current and its application to conduction and excitation in nerve. J. Physiol., 117: 500-544.

Howell, J. N. and Jenden, D. J. (1967) T-tubules of skeletal muscle: morphological alterations which interrupt excitation-contraction coupling. Fed. Proc., 26: 553.

Huxley, A. F. and TAYlor, R. E. (1958) Local activation of striated muscle fibres. J. Physiol., 144: 426-441.

ОотA, I. and NAGAI, T. (1973) Effect of urea on excitation-contraction coupling in frog sartorius muscle. Sapporo Med. J., 42: 83-93.

Peachey, L. (1965) The sarcoplasmic reticulum and the transverse tubules of the frog's sartorius. J. Cell Biol., 75: 709-731.

Podolsky, R. J. (1975) Muscle activation: The current status. Fed. Proc., 34: 1374-1378.

SANDow, A. (1965) Excitation-contraction coupling in skeletal muscle. Pharmacol. Rev., 17: 265-320.

ShANes, A. M. (1958) Electrochemical aspects of physiological and pharmacological action in excitable cells. Pharmacol. Rev., 10: 165-273. 